\title{
Diet and Lifestyle Changes During COVID-19 Lockdown in the United Arab Emirates: Results of a Cross-Sectional Study
}

Hadia Radwan

University of Sharjah

Mahra Al Kitbi

Supreme Council for Family Affairs

Hayder Hasan

University of Sharjah

Marwa Al Hilali

University of Sharjah

Nada Abbas

American University of Beirut

Rena Hamadeh

American University of Beirut

Eman Rashid Saif

American University of Beirut

Farah Naja ( $\nabla$ fn14@aub.edu.lb )

University of Sharjah, American University of Beirut https://orcid.org/0000-0002-8861-3498

Research article

Keywords: COVID-19, Diet, Lifestyle behaviors, UAE, Lockdown

Posted Date: September 16th, 2020

DOl: https://doi.org/10.21203/rs.3.rs-76807/v1

License: (c) (i) This work is licensed under a Creative Commons Attribution 4.0 International License.

Read Full License 


\section{Abstract}

Background: Lockdown measures were implemented in many countries to limit the spread of the COVID19 pandemic. However, such restrictions could precipitate unintended negative consequences on lifestyle behaviors. The main objective of this study was to investigate the prevalence and determinants of unhealthy behavior changes during the COVID-19 lockdown among residents of the United Arab Emirates (UAE).

Methods: A cross-sectional web-based survey of adults residing in the UAE was carried out during lockdown ( $n=2060)$. Using a multi-component questionnaire, the collected data included questions regarding the following lifestyle changes: Increased dietary intake, increased weight, decreased physical activity, decreased sleep, and increased smoking. An unhealthy lifestyle change score was calculated based on the number of unhealthy lifestyle changes each participant reported. In addition, sociodemographic and living conditions information was collected. Descriptive statistics as well as simple and multiple linear regression analyses were used to examine the prevalence and determinants of the unhealthy lifestyle changes considered in this study.

Results: Among the unhealthy lifestyle changes examined, increased food intake was the most common (31.8\%), followed by decreased physical activity (30\%), increased weight (29.4\%), decreased sleep $(20.8 \%)$, and increased smoking (21\%). In addition to identifying the correlates of each of the aforementioned lifestyle changes, the results of the multiple regression linear analyses revealed the following correlates for the overall unhealthy lifestyle change score: females ( $\beta=0.32$, Cl: $0.22 ; 0.42)$, living in an apartment $(\beta=0.12, \mathrm{Cl}: 0.003 ; 0.23)$ and being overweight/obese $(\beta=0.24, \mathrm{Cl}: 0.15 ; 0.32)$ had higher scores, while older adults (>40 years) had lower scores $(\beta=-0.23, \mathrm{Cl}:-0.34 ;-0.12)$.

Conclusion: The COVID-19 lockdown has resulted in a high prevalence of unhealthy lifestyle behaviors and practices among UAE residents. The findings of this study provided the evidence base for officials to design interventions targeting high-risk groups and aiming to improve healthy lifestyle factors among residents during the pandemic.

\section{Background}

Late in 2019, a new coronavirus emerged and called severe acute respiratory syndrome coronavirus 2 (SARS-CoV-2) or coronavirus disease (COVID-19). It is a highly contagious viral disease, which appeared first in Wuhan, China (1) and then rapidly spread within China and worldwide. This leads the World Health Organization (WHO) on March 11, 2020, to acknowledge COVID-19 as a global pandemic (2). As of June 26,2020 , there are close to 10 million confirmed cases in 215 countries (3)and the first detected case in the United Arab Emirates (UAE) was in January 19, 2020 (4) with 46,973 confirmed cases as of June 26, $2020(5)$.

So far there is no radical treatment for the COVID-19 infection, and the only way to battle this pandemic is by increasing awareness and prevention through the implementation of isolation measures and 
enhancement of the function of the immune system $(6,7)$. To combat the COVID-19, many countries have applied preventive measures such as disinfection procedures and partial or complete lockdown to slow the spread of the virus. UAE health authorities are implementing extensive preventative measures to protect public health in line with the World Health Organization's rules and regulations. On March 22, 2020, the UAE authorities applied both strict infection control and partial lockdown (8), which forced many people to stay at home (study and work from home). Nevertheless, such action may exert a sudden and drastic change in the lifestyle of the population. It has been reported that staying at home for a long time may lead to a change in dietary habit, physical activity, and sleep patterns, in addition to psychological impact (9-12).

This new situation may limit access of individuals to daily shopping and affect their choices for a healthy balanced diet with subsequent dependence on highly processed, ready-to-eat cereals and junk foods, which are high in salt, sugar, and fats. Such dietary habits will increase the risk factors of chronic diseases like obesity, heart disease, stroke, type 2 diabetes, some cancers, and chronic kidney disease (13). Moreover, restricted movement due to lockdown may force many people to stay home and to limit their physical activities (9) and results in more sedentary behavior, which is associated with an increased risk of chronic disease (14). Furthermore, it has been reported that the lockdown measures could be associated with distressing experience and boredom because the situation is taking the world into uncharted waters. Such circumstances could be triggered by a loss of usual routine and reduced social and physical contact with others (15). Studies have shown that sleep is crucial for emotional and mental wellbeing and helps to confront stress and anxiety (11). However, sleep patterns of individuals during pandemic containment could be disturbed. Hence, the main objective of this study was to investigate the prevalence and determinants of unhealthy behavior changes during the COVID-19 lockdown among UAE residents, including dietary intake, weight status, physical activity, sleep, and smoking. A secondary objective was to examine the perceptions of healthy practices as well as mental health during the COVID19 lockdown among study participants.

\section{Methodology}

\section{Study design and participants}

A cross-sectional web-based online survey was carried out between the 5th and 18th of May 2020 to investigate the health and dietary practices of adults residing in the UAE during the COVID-19 lockdown in the country. The questionnaire was distributed to 13,500 adults via emails and mobile messages. The list of email addresses and phone numbers was obtained from the database of the Supreme Family Council of Sharjah and their network in the various Emirates of the UAE. Adults, males, and females, aged 18 years and older and residing in the UAE were eligible to complete the questionnaire. Participants ought to be conversant in English or Arabic language. The online survey consisted of a link to an internet-based questionnaire on Google forms with closed-ended questions in English and Arabic. Before starting filling the online survey, participants were presented with information form which described the purpose of the study, procedure, time needed to complete the questionnaire as well as the voluntary nature of 
participation, and the informed consent was written in simple and understandable terms on the first page of the questionnaire. Before enrollment, the participant should agree on the questionnaire, then he /she can proceed with the questionnaire. Ethical approval was obtained from the Research and Ethics Committee at the University of Sharjah (REC-20-05-05-01). The anonymity of the participants was guaranteed during the data collection process.

\section{Questionnaire used in data collection}

In order to compile the list of questions to be included in the survey, a triangulated approach was used. First, a thorough review of the literature was conducted in order to identify the main themes that are important in the context of a lockdown. Second, a group of experts, including a nutritionist, a public health worker, and a community activist deliberated on the context specificity of the themes and formulated the questions to be included within each theme. Lastly, the developed questionnaire (originally written in English) was translated into Arabic and then back-translated into English. An expert who is bilingual and whose native language is Arabic translated into and from Arabic. It was then backtranslated into English by a bilingual expert panel whose native language is English. Both versions of the questionnaire were pilot-tested for clarity and simplicity and logical flow of the questions. Some questions were removed because of redundancy and some were reworded for clarity.

The final version of the questionnaire consisted of 30 questions grouped into four main sections: 1) Sociodemographic characteristics, 2) Dietary habits, 3) Lifestyle practices, and 4) Healthy practices during the COVID-19. The first part included questions related to the socio-demographic profile of the participants (age, gender, marital status, educational level, employment status, region, type of residence, no of children, etc...) and the weight $(\mathrm{kg})$ and height $(\mathrm{cm})$ of the participants. Both weight and height were self-reported by the participants. The body mass index (BMI) was calculated by dividing the weight (in $\mathrm{kg}$ ) by the height (in $\mathrm{m}^{2}$ ). Participants were then classified into four categories, underweight $\left(<18.5 \mathrm{~kg} / \mathrm{m}^{2}\right)$, normal (18.5-24.9 kg/m2), overweight $\left(25.0-29.9 \mathrm{~kg} / \mathrm{m}^{2}\right)$, and obese $\left(\geq 30.0 \mathrm{~kg} / \mathrm{m}^{2}\right)(\mathrm{WHO}, 2004)$. The second part of the questionnaire included questions related to dietary habits. The focus was on the quantity and quality of the diet, such as the amount of food consumed during lockdown (decrease, same or increased), the type of foods that were mostly consumed during the lockdown, and which foods' intake increased during the lockdown. The section addressing the lifestyle included questions related to weight changes (decreased, same, increased), physical activity (decreased, same, increased); smoking (decreased, same, increased) and the number of hours of sleep per day (decreased, same, increased). With regards to the healthy practices during COVID-19, participants were asked if they wore masks and gloves when going out, the frequency of grocery shopping, and if they disinfected and sterilized the food items purchased. The questionnaire required approximately 10 minutes to complete. The questionnaire was included in this manuscript as Appendix A.

\section{Statistical analysis}

Data analysis was conducted using IBM SPSS statistics software version 25 for Windows. Descriptive statistics were presented as frequency and percentage. The main outcomes were unhealthy dietary and 
lifestyle changes described as decreased physical activity (vs same or increased), decreased sleep (vs same or increased), increased smoking (vs same or increased and non-smokers), increased weight (vs same or decreased) and increased food intake (vs same or decreased). An unhealthy dietary and lifestyle changes score was generated whereby participants will receive 0 to 5 points based on the number of unhealthy dietary and lifestyle changes they presented. A higher score indicated a higher adoption of unhealthy lifestyle during the lockdown. Simple and multiple logistic regressions were conducted to describe the associations between each of the aforementioned outcomes (decreased physical activity, decreased sleep, increased smoking, increased weight and increased food intake), and sociodemographic characteristics of the study population. Simple and multiple linear regression analysis were used for the association between the unhealthy dietary and lifestyle changes score and sociodemographic characteristics. In the adjusted models, variables with a significant $p$-value $(<0.05)$ at the univariate level were entered in the model. Results of the logistic and linear regression models were expressed, respectively, as Odds Ratios (OR) and $\beta$ coefficient with 95\% Confidence Intervals (CI). P-values less than 0.05 were considered statistically significant.

\section{Results}

Out of 13,500 sent links, 2,135 responses were received. Of those, 2,060 were returned with complete answers, resulting in a response rate of $15.8 \%$. Table 1 described the sociodemographic characteristics of the study population. Three-quarters (75.1\%) were females, $31.7 \%$ were between 18 and 30 years old, $38.4 \%$ were between 31 and 40 years old, and $29.9 \%$ were older than 40 years. Over half of the study population $(63.8 \%)$ were married and the majority had a university degree $(76 \%)$. One in two participants was an Emirati (50.7\%), the rest of the sample was distributed as follows: Arabs (33.4\%), Asians (12.4\%), Western (2.4\%), and other nationalities (1.1\%). The most commonplace of residence was Sharjah (68\%) followed by Dubai (11.8\%), Ajman (8.8\%), Abu Dhabi (5.8\%), Ras Al Khaima (RAK) (2.6\%), Umm Al Quwain (UAQ) (1.6\%) and Fujairah (1.4\%). Almost two-thirds (60.7\%) reported living in a house with a garden or yard. One in four $(25.5 \%)$ were not working at the time of completing the questionnaire and $54.8 \%$ were working from home. Among the study participants, $38.4 \%$ had no children, $30 \%$ had 1 or 2 children and $31.7 \%$ had 3 or more. In terms of BMI status, $64.7 \%$ of the study population were either overweight or obese ( $\geq$ BMl of $25 \mathrm{~kg} / \mathrm{m}^{2}$ ). (Table 1). 
Table 1

Sociodemographic characteristics of the study population $(n=2060)$.

\begin{tabular}{|c|c|c|c|}
\hline & & $\mathbf{n}$ & $\%$ \\
\hline \multirow[t]{2}{*}{ Gender } & Male & 512 & 24.9 \\
\hline & Female & 1548 & 75.1 \\
\hline \multirow[t]{3}{*}{ Age (years) } & $18-30$ & 654 & 31.7 \\
\hline & $31-40$ & 791 & 38.4 \\
\hline & $>40$ & 615 & 29.9 \\
\hline \multirow{3}{*}{ Marital status } & Single & 639 & 31.0 \\
\hline & Married & 1315 & 63.8 \\
\hline & Ever married & 106 & 5.1 \\
\hline \multirow[t]{2}{*}{ Education } & Up to high school \& technical diploma & 494 & 24.0 \\
\hline & University & 1566 & 76.0 \\
\hline \multirow[t]{5}{*}{ Nationality } & Emirati & 1044 & 50.7 \\
\hline & Arabic & 688 & 33.4 \\
\hline & Western & 49 & 2.4 \\
\hline & Asian & 256 & 12.4 \\
\hline & Other & 22 & 1.1 \\
\hline \multirow[t]{7}{*}{ Emirates of residence } & Sharjah & 1401 & 68.0 \\
\hline & Dubai & 243 & 11.8 \\
\hline & Abu Dhabi & 119 & 5.8 \\
\hline & Ras El Khaimah (RAK) & 54 & 2.6 \\
\hline & Fujairah & 29 & 1.4 \\
\hline & $U A Q$ & 32 & 1.6 \\
\hline & Ajman & 182 & 8.8 \\
\hline \multirow[t]{2}{*}{ Type of living } & In a house with a garden or yard & 1250 & 60.7 \\
\hline & In an apartment/a house with no garden or yard & 810 & 39.3 \\
\hline Working status & Not working & 525 & 25.5 \\
\hline
\end{tabular}

Abbreviations: BMI: Body Mass Index. 


\begin{tabular}{|llll|}
\hline & & $\mathbf{n}$ & $\%$ \\
\hline & working from home & 1129 & 54.8 \\
\hline Norking & 406 & 19.7 \\
\hline & None & 791 & 38.4 \\
\hline BMI $\left(\mathbf{k g} / \mathbf{m}^{2}\right)$ & $1-2$ & 617 & 30.0 \\
\hline & Normal (<25) & 652 & 31.7 \\
\hline Abbreviations: BMl: Body Mass Index. & 728 & 35.3 \\
\hline
\end{tabular}

The description of the lifestyle behaviors as well as the overall unhealthy lifestyle score is presented in Table 2. For all the lifestyle characteristics considered, almost $50 \%$ of the study population did not change behavior (physical activity (53.5\%); food intake (51.5\%), weight status (47.5\%), smoking (40\%), and sleep (53.9\%)). As for the overall unhealthy lifestyle score, $30 \%$ of participants had a score of 0 , indicating no unhealthy change in any of the behaviors. $62.1 \%$ had 1 or 2 unhealthy behaviors and $9 \%$ had 3 or more unhealthy behaviors. 
Table 2

Description of dietary and lifestyle behaviors changes during COVID-19 pandemic among the study population ( $\mathrm{n}$ $=2060$ )

\begin{tabular}{|c|c|c|c|}
\hline & & $\mathbf{n}$ & $\%$ \\
\hline \multirow[t]{3}{*}{ Physical activity } & Increase & 340 & 16.5 \\
\hline & Decrease $^{b}$ & 618 & 30.0 \\
\hline & Same & 1,102 & 53.5 \\
\hline \multirow[t]{3}{*}{ Food intake } & Increase ${ }^{b}$ & 655 & 31.8 \\
\hline & Decrease & 344 & 16.7 \\
\hline & Same & 1,061 & 51.5 \\
\hline \multirow[t]{3}{*}{ Weight } & Increase $^{b}$ & 606 & 29.4 \\
\hline & Decrease & 476 & 23.1 \\
\hline & Same & 978 & 47.5 \\
\hline \multirow[t]{3}{*}{ Smoking a } & Increase ${ }^{b}$ & 50 & 21.0 \\
\hline & Decrease & 93 & 39.1 \\
\hline & Same & 95 & 39.9 \\
\hline \multirow[t]{3}{*}{ Sleep } & Increase & 522 & 25.3 \\
\hline & Decrease ${ }^{b}$ & 428 & 20.8 \\
\hline & Same & 1,110 & 53.9 \\
\hline \multirow{3}{*}{$\begin{array}{l}\text { Unhealthy lifestyle score } \\
\text { (Mean } \pm \text { SD: } 1.14 \pm 0.96 \text { ) }\end{array}$} & 0 & 595 & 28.9 \\
\hline & $1-2$ & 1279 & 62.1 \\
\hline & $\geq 3$ & 186 & 9.0 \\
\hline \multicolumn{4}{|c|}{ a percentage among smokers $(N=238)$} \\
\hline b considered unhealthy & aviors & & \\
\hline
\end{tabular}

The prevalence of each of the five unhealthy behaviors considered in this study is illustrated in Fig. 1. Increased food intake was the most common, reported by $31.8 \%$, followed by decreased physical activity (30\%), and increased weight (29.4\%). Decreased sleep and increased smoking were reported by $20.8 \%$ and $21 \%$, respectively. 
The associations of each of these unhealthy lifestyle changes with sociodemographic characteristic, as examined by simple and multiple logistic regression are summarized in appendix B. Regarding increased food intakes, female sex, being Non-Emirati Arabic (vs Emirati), having 1-2 children (vs none), and being overweight or obese were risk factors for increased food intake (females: OR: 1.87, Cl: 1.47-2.39; being an Arab: OR: 1.35, Cl: 1.02-1.79; having 1-2 children: OR: 1.33, Cl: 1.05-1.68; Being overweight or obese: OR: 1.47, Cl: 1.19-1.82). On the other hand, being 40 years old (vs 18-30 years old) was associated with a lower odd of increasing food intake (OR: 0.57, Cl: 0.43-0.86). As for increased weight, the following characteristics were associated with higher odds: females (OR: 1.89, Cl: 1.47-2.41), Non-Emirati Arabic (OR: 1.62, Cl: 1.22-2.17), Western (OR: 2.06, Cl: 1.08-3.93), Asian nationalities (OR: 1.70, Cl: 1.15-2.50), living in an apartment or house with no garden or yard (OR: 1.51, Cl: 1.15-1.98), and being overweight or obese (OR: 2.25, Cl: 1.79-2.83). Decreased physical activity was significantly associated with age, nationality, working from home and BMl: older adults aged more than 40 years ( $0: 1.61, \mathrm{Cl}: 1.25-2.08)$, working from home (OR: 0.7, Cl: 0.53-0.93) and overweight or obese (adj OR: 1.38, Cl: 1.13-1.72). As for increased smoking behavior, females and older adults ( $>40$ years old vs $18-30$ years old) were less likely to increase their smoking behavior during the lockdown (for females ORs 0.27, $\mathrm{Cl} 0.15-0.49$; for older adults: OR: 0.25 , Cl: $0.11-0.57)$. In terms of sleeping behavior, females were more likely to experience decreased sleep compared to males, whereas older adults ( $>40$ years old vs 18-30 years old) were less likely to experience decreased sleep during the lockdown. (Appendix B).

The association of the unhealthy lifestyle and dietary behaviors score with sociodemographic variables are shown in Table 3. The results of the multiple regression analyses showed that females were more likely to have a higher score (Coef. 0.32 , Cl: $0.22 ; 0.42$ ) as well as those living in an apartment or a house with no garden or yard (vs in a house with a garden or yard) (Coef. $0.12, \mathrm{Cl}: 0.003 ; 0.23$ ) and those whose $\mathrm{BMI} \geq 25 \mathrm{~kg} / \mathrm{m}^{2}$ (Coef. 0.24 , Cl: $0.15 ; 0.32$ ). On the other hand, older adults ( $>40$ years old) were more likely to have a lower score compared to 18 to 30 years old adults (Coef. -0.23 , Cl: $-0.34 ;-0.12$ ). (Table 3 ) 
Table 3

Simple and multiple linear regressions describing the association between unhealthy lifestyle score and sociodemographic characteristics in the study population $(n=2060)$.

Unhealthy lifestyle Score $(n=2060)$

$\begin{array}{llll}\begin{array}{l}\text { Crude } \\ \text { coef. }\end{array} & 95 \% \mathrm{Cl} & \begin{array}{l}\text { adj } \\ \text { coef. }\end{array} & 95 \% \mathrm{Cl}\end{array}$

\section{Sex (ref: males)}

Female

0.26

$(0.16 ; 0.35) \quad 0.32$

$(0.22 ; 0.42)$

Age (ref 18-30)

$31-40$

$-0.09$

$(-0.19 ; 0.01)$

$-0.11$

$(-0.21$;

$-0.01)$

$>40$

$-0.19$

$(-0.3 ;-0.09) \quad-0.23$

$(-0.34$

$-0.12)$

Marital status (ref: Single)

Married

$-0.06$

$(-0.15 ; 0.03)$

Ever married

$-0.07$

$(-0.27 ; 0.13)$

\section{Education (ref: up to high school)}

University

$-0.07$

$(-0.16 ; 0.03)$

Nationality (ref: Emirati)

Arabic

0.1

(0.003;

0.08

$(-0.04 ; 0.2)$

0.19 )

Western

Asian

Other

Type of living (ref: house with a garden or yard)

An apartment/house with no garden or yard

0.12

$(-0.17 ; 0.38)$

0.12

$(-0.16 ; 0.4)$

0.1

0.03

$(-0.1 ; 0.16)$

0.03

$(-0.19 ; 0.62)$

0.14

$(-0.12 ; 0.19)$

0.21

$(-0.19 ; 0.62)$

$(-0.27 ; 0.54)$

$(0.04 ; 0.21)$

0.12

(0.003;

\section{Working Status (ref: Not working)}

Working from home

$-0.1$

$0.23)$

Abbreviations: BMI: Body Mass Index, Coef.: Coefficient, adj coef: adjusted coefficient, Cl: Confidence interval.

The adjusted models include all the variables that were significant ( $p$-value $<0.05)$ at the crude level.

Numbers in bold are statistically significant ( $p$-value $<0.05)$ 


\section{Unhealthy lifestyle Score $(n=2060)$}

Working $\quad-0.02 \quad(-0.15 ; 0.1) \quad 0.09 \quad(-0.04 ; 0.21)$

\section{Number of Children (ref: 0 )}

$\begin{array}{lll}1-2 & 0.08 & (-0.03 ; 0.18) \\ >3 & -0.02 & (-0.12 ; 0.08)\end{array}$

\section{BMI $\left(\mathrm{kg} / \mathrm{m}^{2}\right)($ ref: $<25)$}

$>$ or $=25$

0.15

$(0.06 ; 0.24) \quad 0.24$

$(0.15 ; 0.32)$

Abbreviations: BMI: Body Mass Index, Coef.: Coefficient, adj coef: adjusted coefficient, Cl: Confidence interval.

The adjusted models include all the variables that were significant ( $p$-value $<0.05)$ at the crude level. Numbers in bold are statistically significant ( $p$-value $<0.05)$

Perception, health, and dietary practices and perceived mental health status related to COVID-19 among the study population were described in Table 4. When asked about their agreement on "Quarantine is a good way to protect my family and to stop the spread of infectious disease outbreaks", $98.4 \%$ of the participants agreed. When going out, $83 \%$ reported using both gloves and masks, $14.7 \%$ used masks only, $1.3 \%$ gloves only, and $1.1 \%$ haven't used any. With regards to dietary practices, a vast majority $(90.8 \%)$ reported home-cooked food as one of the most consumed food items during the COVID-19 pandemic. The next most reported items were fruits and vegetables (60.2\%, each), herbal tea (37\%), nuts (34.3\%), and sweets (32.6\%). As for the type of food the participants consumed more during the COVID-19 pandemic, $84.4 \%$ chose cooked food while $21.3 \%$ chose salty snacks, $7.1 \%$ sweet sacks and only $5.7 \%$ chose nothing. The proportion of going grocery shopping increased by $4 \%$ of the study population, remained the same for 22.1 , and decreased for $22.9 \%$ while $51 \%$ reported no definite number of times of going grocery shopping. Almost half (48\%) of the participants reported ordering food or groceries for delivery and $79.4 \%$ sterilize food items when delivered. The most common ways reported to disinfect purchased fruits and vegetables were water only $(43.8 \%)$, water and vinegar $(21.9 \%)$ and water, vinegar, and salt $(9.8 \%)$ whereas $1.8 \%$ reported not disinfecting purchased fruits and vegetables. The participants were asked if they felt angrier and stressed during lockdown, $41.8 \%$ reported that they felt angrier and $67.2 \%$ were more stressed during lockdown. When asked what they did to relieve stress, the majority reported they prayed (33\%) or watched movies/ listened to music / social media (27\%) to relieve their stress. While the rest either ate more $(10.5 \%)$, some exercised $(10.2 \%)$, or meditated $(10.1 \%)$ to relieve stress. 
Table 4

Description of, perception, health and dietary practices, and perceived mental health status related to COVID-19 among the study population $(n=2060)$.

\begin{tabular}{|c|c|c|c|}
\hline & & $\mathrm{n}$ & $\%$ \\
\hline \multicolumn{4}{|l|}{ Health practices } \\
\hline \multirow{2}{*}{$\begin{array}{l}\text { Agreement on "Quarantine is a good way to protect my } \\
\text { family and to stop the spread of infectious disease } \\
\text { outbreaks" }\end{array}$} & Agree & 2028 & 98.4 \\
\hline & Disagree & 32 & 1.6 \\
\hline \multirow[t]{4}{*}{ Gloves and Mask use when going out } & Gloves & 26 & 1.3 \\
\hline & Mask & 303 & 14.7 \\
\hline & Both & 1709 & 83 \\
\hline & None & 22 & 1.1 \\
\hline \multicolumn{4}{|l|}{ Dietary practices } \\
\hline \multirow{12}{*}{$\begin{array}{l}\text { Food items consumed the most during COVID-19 } \\
\text { pandemic }\end{array}$} & Home cooked food & 1871 & 90.8 \\
\hline & Vegetables & 1240 & 60.2 \\
\hline & Fruits & 1240 & 60.2 \\
\hline & Herbal tea & 762 & 37.0 \\
\hline & Nuts & 707 & 34.3 \\
\hline & Sweets & 672 & 32.6 \\
\hline & Cakes and pastries & 548 & 26.6 \\
\hline & Chips and crackers & 485 & 23.5 \\
\hline & Fried food & 379 & 18.4 \\
\hline & Delivery food & 127 & 6.2 \\
\hline & Fast food & 92 & 4.5 \\
\hline & None & 85 & 4.1 \\
\hline \multirow{4}{*}{$\begin{array}{l}\text { Type of food the participants' consumed more of during } \\
\text { COVID-19 pandemic }\end{array}$} & Cooked food & 1739 & 84.4 \\
\hline & $\begin{array}{l}\text { Salty Snacks: chips, } \\
\text { popcorn, crackers etc. }\end{array}$ & 439 & 21.3 \\
\hline & $\begin{array}{l}\text { Sweet snacks: } \\
\text { Cupcakes, cookies, } \\
\text { cakes, etc. }\end{array}$ & 147 & 7.1 \\
\hline & Nothing/Other & 117 & 5.7 \\
\hline Number of times went grocery shopping per week during & Increase & 83 & 4.0 \\
\hline
\end{tabular}




\begin{tabular}{|c|c|c|c|}
\hline & & $\mathrm{n}$ & $\%$ \\
\hline \multirow[t]{3}{*}{$\begin{array}{l}\text { COVID-19 lockdown as compared to before COVID-19 } \\
\text { lockdown }\end{array}$} & Decrease & 471 & 22.9 \\
\hline & Same & 456 & 22.1 \\
\hline & $\begin{array}{l}\text { No definite number of } \\
\text { times }\end{array}$ & 1050 & 51.0 \\
\hline \multirow[t]{7}{*}{ Dietary Ways to disinfect purchased fruits and vegetables } & water & 902 & 43.8 \\
\hline & Water + salt & 107 & 5.2 \\
\hline & Water + Vinegar & 451 & 21.9 \\
\hline & Water + Vinegar + salt & 201 & 9.8 \\
\hline & $\begin{array}{l}\text { Water + Detergents } \\
\text { (Dishwashing liquid) }\end{array}$ & 176 & 8.5 \\
\hline & $\begin{array}{l}\text { Disinfectants for } \\
\text { vegetables and fruits }\end{array}$ & 186 & 9.0 \\
\hline & None & 37 & 1.8 \\
\hline \multirow[t]{2}{*}{ Dietary Ordering food or groceries for delivery } & Yes & 989 & 48.0 \\
\hline & No & 1071 & 52.0 \\
\hline \multirow[t]{2}{*}{ Dietary Sterilizing food items when delivered } & Yes & 1636 & 79.4 \\
\hline & No & 424 & 20.6 \\
\hline \multicolumn{4}{|l|}{ Perceived mental health status and practices } \\
\hline \multirow[t]{2}{*}{ Feeling angry more during the lockdown } & Yes & 860 & 41.7 \\
\hline & No & 1200 & 58.3 \\
\hline \multirow[t]{2}{*}{ Feeling more stressed during lockdown } & Yes & 1385 & 67.2 \\
\hline & No & 1200 & 58.3 \\
\hline \multirow[t]{6}{*}{ Practices to relieve stress during lockdown } & Pray & 679 & 33.0 \\
\hline & $\begin{array}{l}\text { Watch } \\
\text { movies/music/social } \\
\text { media }\end{array}$ & 554 & 26.9 \\
\hline & Eat more & 216 & 10.5 \\
\hline & Exercise more & 209 & 10.2 \\
\hline & Meditate & 210 & 10.1 \\
\hline & $\begin{array}{l}\text { Other (reading, talking } \\
\text { to friend, etc...) }\end{array}$ & 129 & 6.3 \\
\hline
\end{tabular}




\section{Discussion}

The strategy adopted by many countries, as well as UAE to reduce the spread of COVID-19 has been "social distancing" and home quarantine. The tight precautionary measures that the UAE government imposed to curb the COVID-19 epidemic were needed to control the spread of the Coronavirus and mitigate the strains on the healthcare system. The majority of UAE residents, as reflected in this study, agreed that quarantine and wearing gloves and masks rules were effective ways to reduce the spread of Covid-19 pandemic virus. Although these restrictions were effective in flattening the curve of the epidemic, they could precipitate unintended negative consequences on lifestyle behaviors among the UAE residents. To that effect, this population-based survey was designed to provide a description of the unhealthy changes in lifestyle and their determinants among UAE residents during the Covid-19 lockdown, including decreased physical activity, increased food intake, increased weight, increased smoking, and decreased sleep. Among these changes, the highest prevalence was for increased food intake followed by decreased physical activity, increased weight, increased smoking, and decreased sleep. Over half of the study participants (62\%) had one or two unhealthy lifestyle changes during the lockdown with $9 \%$ reporting more than 3 . Except for increased smoking, females had higher odds of adopting unhealthy lifestyle changes as compared to males. Older adults were less likely to adopt any of these changes, with the exception of physical activity. Non-Emirati Arabs as compared to Emiratis were more likely to report an increase in their food intake, weight, and smoking. Living in an apartment, as opposed to living in a house with a yard or garden, or being overweight or obese increased the odds of all the lifestyle changes except for sleep where no associations were found. For the overall score on unhealthy lifestyle, females, living in an apartment and being overweight or obese were predictors of higher scores while older age was associated with lower values of the score. In addition to these findings, the study showed that almost half of the study population were angry and felt more stressed during the lockdown.

The findings of this study showed that the most prevalent unhealthy change in behavior among participants was increased food intake (32\%). The confinement to one's home and the interruption of the work-related routine could lead to irregular eating patterns and frequent snacking, both of which are associated with increased food intake and consequently a more positive caloric balance (16.). Such an increase in food intake could also be driven by fear and anxiety. During the quarantine, continuously hearing or listening about the pandemic spread and its associated mortality can be stressful (17). In fact, in this study more half of the participants reported anger and heightened levels of stress during the lockdown. For many people, the response to stress, distress, and emotional disturbance is not to avoid food but possibly to increase the consumption of energy-dense foods (18). It has been proposed that this emotionally-induced eating comes as a result of interference of eating by emotions, a by-product of emotions, and a consequence of regulatory processes (i.e., emotions may regulate eating, and eating may regulate emotions) (19). Of concern is the finding of this study that salty and sweet snacks (chips, crackers, cupcakes, cookies) were reported among the foods in which intake has increased most during lockdown. These foods are usually calorie-dense and also high in salt, sugar, saturated fats $(20,21)$. In addition, the higher consumption of these foods could displace more nutritious options in the diet such as fruits and vegetables. During the COVID-19 pandemic, optimal nutrition intake is paramount given its 
significant effects on the immune system. In fact, adequate dietary nutrient intakes are postulated to directly affect immunity through gene expression, cell activation, and signaling molecule modifications. In addition, many nutrients are implicated in the proper functioning of the gut microbiota and its composition and hence indirectly modulating the immune response (22). Therefore, promoting the adoption and maintenance of a healthy and well-balanced diet seems to be a prerequisite for a strong and well-functioning immune system that could withstand the assault of infections, including that of the Coronavirus.

In this study, one in three participants reported lower physical activity levels during lockdown. This significant prevalence of lower physical activity was also reported by a cross-sectional survey among Lebanese adults, whereby $41 \%$ reported no physical activity or exercise during lockdown (23). In fact, staying home for a prolonged period of time may lead to more prevalent sedentary behavior such as excessive sitting/reclining, increased screen time activities (video games, TV watching, use of mobile devices) (24). The negative consequences of the decrease in physical activity observed during COVID-19 affect both the physical and mental health. On one hand, lower physical activity levels lead to lower energy expenditure, a higher risk of overweight, obesity, and hence worsening of chronic health conditions (25). In addition, lower levels of exercise have been shown to lower the immune competency and regulation and increase the risk of developing systemic inflammation (26). Furthermore, accumulating evidence indicated that regular physical activity is beneficial for mental health as it reduces anxiety, depression, and negative mood, and improves self-esteem and improves the overall quality of life (27). These negative effects of lower physical activity on health, including a higher risk of chronic diseases, lower immunity, and compromised mental health, were in fact implicated in more severe symptoms and worse outcome for COVID-19 $(25,28,29)$. Therefore, it is recommended to continue to maintain a healthy level of physical activity in a safe home environment using simple and easily implementable exercises such as walking in the house, lifting and carrying objects such groceries, alternating leg lunges, climbing the stairs, stand-to-sit and sit-to-stand using a chair and from the floor, and sit-ups and pushups. In addition, recently there has been an abundance of eHealth and exercise videos, which focuses on encouraging and delivering physical activity through the Internet, mobile technologies, and television (30).

The third most common unhealthy lifestyle behavior among study participants, after the increase in food intake and decreased physical activity was 'increased weight'. It is, in fact, conceivable that these three unhealthy behaviors are interconnected, whereby the higher intake of food coupled to lower levels of physical activity would lead to a positive energy balance, a weight gain, and higher risk of overweight and obesity. Increasing evidence indicated that obesity is strongly associated with severe symptoms and death from COVID-19 (31-33). For instance, the risk for invasive mechanical ventilation in patients with COVID-19 infection admitted to the Intensive Treatment Unit increased by seven-fold for those with BMI > 35 compared with $\mathrm{BMI}<25 \mathrm{Kg} / \mathrm{m}^{2}$ (31). In their review of the potential mechanisms by which obesity affects the disease outcome, Sattar et al. suggested that obesity and ectopic fat may lower the cardiorespiratory fitness, increase the cardiovascular susceptibility to immune driven vascular and thrombotic effects, impaired metabolic response, dysregulate the immune response and increase viral exposure, through more viral shedding and viral load in the breath (34). The higher risk of overweight and obesity 
during COVID-19 observed in this study is rather alarming when considered in the context of the UAE. Recent population-wide data (before the pandemic) showed that over $65 \%$ of adults residing in the UAE were already either overweight or obese, with $57 \%$ having central obesity (35). This high prevalence of obesity is accompanied by a heavy burden of Non-communicable diseases (NCDs) in the country, where the four main NCDs accounted for $77 \%$ of all deaths in UAE and $17 \%$ of premature deaths (30-70 years) in the year 2019 (36). Therefore, public health intervention tackling the prevention and management of obesity in the country is needed, now more than ever, in order to not only prevent chronic diseases but also limit the adverse reactions to viral pandemics. Decreased sleep and increased smoking were also among the unhealthy lifestyle changes which were reported in this study. Similar to these findings, previous studies showed that, among individuals who were self-isolated during the COVID-19 outbreak, a worsening of sleep duration and quality was observed (37). Furthermore, a survey of lifestyle habits conducted in Poland showed that over $45 \%$ of smokers experienced a rise in smoking frequency during the quarantine (38). Both decreased sleep and increased smoking can potentially increase vulnerability to infection by the coronavirus and worsen the clinical symptoms of COVID-19. Sleep is an important modulator of the immune response, whereby shorter duration of sleep was associated with a weaker immunity and an increased susceptibility to infection (39). Suggested mechanisms for this association included impaired mitogenic proliferation of lymphocytes, decreased HLA-DR expression, the upregulation of CD14+, and variations in CD4 + and CD8 + T lymphocytes (39). As for smoking, a review of its association with immunity indicated significant impacts of smoking on both innate and adaptive immunity by either exacerbation of pathogenic immune responses or attenuation of defensive immunity (40).

The unhealthy lifestyle changes described in this study call for evidence-based interventions to limit the undesirable effect of lockdown on the health of adults in the UAE, especially among population groups that exhibit a higher likelihood to adopt these unhealthy changes. To that effect, the findings of this study showed that females compared to males were more likely to report increased dietary intake, increased weight, lower physical activity, and decreased sleep. The vulnerability of women to such changes in their lifestyle could be explained by the fact that women, in general, are more susceptible to emotional exhaustion, stress, and their negative health implications (41). In this study, participants living in an apartment with no yard or garden were more likely to report all of the unhealthy lifestyle changes, except for decreased sleep. This finding underscores the role of built environment in affecting the lifestyle of individuals. A growing body of evidence supports built environment as a health promoter of individuals and communities by influencing risk factors, such as dietary choice and physical activity (42). In addition to gender and living conditions, weight status was shown to affect the odds of adopting unhealthy behaviors, whereby in this study, having a $\mathrm{BMI} \geq 25 \mathrm{~kg} / \mathrm{m}^{2}$ were more likely to report higher dietary intake, increase in weight, lower physical activity and increased smoking. It has been suggested that during quarantine, patients suffering from obesity may experience higher levels of stress which in turn makes them more vulnerable to over-eating and sedentary lifestyle, thus predisposing them to further weight gain (18). These findings suggest that obese subjects must be carefully informed about the risk of an unhealthy lifestyle during the quarantine due to the increasing risk of disease associated with obesity. In 
addition, it is important for overweight and obese subjects to carefully monitor their health and to receive strong psychological support to reduce their stress and anxiety levels.

In this study, among the factors that were associated with lower odds of adopting unhealthy lifestyle changes was older age ( $>40$ years). While older adults were at a higher risk of complications and severity of the coronavirus infection (43-45), it appeared that younger individuals seemed to be more vulnerable to the effect of confinement and exhibited an overall higher frequency of unhealthy changes in their lifestyles. It is possible that younger adults are less prepared to cope with the lockdown and its consequences as well as stress, anxiety, and fear.

The findings of this study ought to be considered in view of a couple of limitations. First, the online nature of the survey limits the ability to objectively verify the data. As such all the changes in the lifestyle are based on self-reports and could have been subject to self-selection and reporting bias. However, given the lockdown situation in the UAE, face-to-face data collection was not possible. Second, the low response rate in this survey could have resulted in a non-response bias and hence limit the generalizability of the findings. Such low response rate of the online survey has been previously reported, however, in the case of this study, the advantages of this method (speed, cost, no physical contact) outweighed its disadvantages and potential biases.

\section{Conclusions}

Since the outbreak of the COVID-19 pandemic, restrictive measures of confinement and lockdown were imposed in many countries around the world, including the UAE. Although efficient in limiting the spread of the virus, such measures could have detrimental consequences on the lifestyle and wellbeing of individuals. Among potential unhealthy lifestyle changes that could propagate during lockdown are increased dietary intake, increased weight, decreased physical activity, increased smoking, and decreased sleep. The findings of this study highlighted that over half of adults residing in the UAE had one or two of the aforementioned unhealthy lifestyle changes during the lockdown with $9 \%$ reporting more than 3 . The female gender, living in an apartment and being overweight or obese were more likely to report unhealthy lifestyle changes. In addition, almost half of the study population were angry and felt more stressed during the lockdown. Such findings are important to consider in a country such as UAE, given its high burden of diseases related to unhealthy lifestyle, namely the NCDs. Residents in the UAE should be encouraged to improve their lifestyle to lessen the risk both in the current and subsequent waves of COVID-19. Concerted efforts are needed to develop interventions aiming to alleviate the impact of lockdown on diet and lifestyle. Promoting a healthy diet, regular at-home exercises, avoiding smoking, and working on mental health are key factors to be considered to improve in boosting the immune system. Using the e-platforms for the design and delivery of these interventions to help people adopt sustainable changes could constitute an opportunity for which future studies are needed to determine feasibility and efficacy.

\section{List Of Abbreviations}


UAE: United Arab Emirates; COVID-19: Coronavirus Disease; SARS-COVID-2: Syndrome Coronavirus; WHO: World Health Organization; BMI: Body Mass Index; OR: Odds Ratio; UAQ: Umm Al Quwain; RAK: Ras Al Khaima; Coef: Coefficient; Adj Coef: Adjusted Coefficient; Cl: Confidence Interval; NCD: NonCommunicable Diseases.

\section{Declarations}

\section{Funding:}

No funding is applicable.

\section{Conflict of Interest:}

The authors declare that they have no competing interests.

\section{Ethics approval and consent to participate:}

The Research and Ethics Committee at the University of Sharjah (REC-20-05-05-01) approved the study protocol. Written informed consent was obtained from participants before enrollment in the study.

\section{Consent for publication:}

Not Applicable

\section{Availability of data and material:}

The datasets used and/or analyzed during the current study are available from the corresponding author on reasonable request.

\section{Authors' Contributions:}

HR, MAK, and FN led the conceptualization of the study. HR, MAK, ERS designed the web-survey. MAK, $\mathrm{HH}, \mathrm{MAH}$, and ERS supervised data collection and prepared the data for analysis. $\mathrm{HH}, \mathrm{NA}, \mathrm{RH}$ conducted the statistical analysis and tabulation of the data. $\mathrm{HH}, \mathrm{HR}, \mathrm{NA}$ prepared the first draft of the manuscript. FN led the critical review of data analysis, interpretation as well as the write up of the final draft of the manuscript. All authors have read and approved the final version of the manuscript.

\section{Acknowledgments:}

We would like to thank the staff in the Health Promotion Department in the Supreme Council for Family Affairs-Sharjah for facilitating and coordinating data collection. Moreover, our greatest gratitude goes to all participants for their time in completing the survey.

\section{References}


1. Zhou F, Yu T, Du R, Fan G, Liu Y, Liu Z, et al. Clinical course and risk factors for mortality of adult inpatients with COVID-19 in Wuhan, China: a retrospective cohort study. The lancet. 2020.

2. Ghebreyesus TA. WHO Director-General's opening remarks at the media briefing on COVID-19-11 March 2020. World Health Organization. 2020;11.

3. Worldometer CC. Worldometer.(2020) 1-22. Doi.10(2020.01):23.20018549.

4. The National Newspaper, Coronavirus: UAE records first case - The National, (2020). 2020 [Available from: https://www.thenational.ae/uae/health/coronavirus-uae-records-first-case-1.971253.

5. Worldometer. United Arab Emirates Coronavirus: 44,145 Cases and 300 Deaths 2020 [Available from: https://www.worldometers.info/coronavirus/country/united-arab-emirates/.

6. Edward-Elmhurst Health. How to boost your immune system during COVID-19 2020 [Available from: https://www.eehealth.org/blog/2020/05/how-to-boost-your-immune-system-during-covid-19/.

7. CDC. Center for Disease Control and Prevention, Quarantine and Isolation | Quarantine | CDC 2017 [Available from: https://www.cdc.gov/quarantine/index.html.

8. Forbes. Dubai Enters 24-Hour Lockdown As Travel Restrictions Extended In UAE 2020 [Available from: https://www.forbes.com/sites/jamesasquith/2020/04/05/dubai-enters-24-hour-lockdown-astravel-restrictions-extended-in-uae/\#7e1b9a8d4f31.

9. The Independent. Coronavirus: Adult physical activity falls by a quarter since lockdown I The Independent 2020 [Available from: https://www.independent.co.uk/life-style/health-andfamilies/coronavirus-lockdown-physical-activity-reduced-exercise-weight-a9505411.html.

10. Di Renzo L, Gualtieri P, Pivari F, Soldati L, Attinà A, Cinelli G, et al. Eating habits and lifestyle changes during COVID-19 lockdown: an Italian survey. Journal of Translational Medicine. 2020;18(1):1-15.

11. Sleep Foundation. Sleep Guidelines and Help During the COVID-19 Pandemic 2020 [Available from: ttps://www.sleepfoundation.org/sleep-guidelines-covid-19-isolation

12. Brooks SK, Webster RK, Smith LE, Woodland L, Wessely S, Greenberg N, et al. El impacto psicológico de la cuarentena y cómo reducirla: revisión rápida de las pruebas. Lancet. 2020;395:912-20.

13. Australian Dietary Guidelines, Fat, salt, sugars and alcohol | Eat For Health 2015 [Available from: https://www.eatforhealth.gov.au/food-essentials/fat-salt-sugars-and-alcohol.

14. Katzmarzyk P, Lear S. Physical activity for obese individuals: a systematic review of effects on chronic disease risk factors. Obesity Reviews. 2012;13(2):95-105.

15. Hawryluck L, Gold WL, Robinson S, Pogorski S, Galea S, Styra R. SARS control and psychological effects of quarantine, Toronto, Canada. Emerging infectious diseases. 2004;10(7):1206.

16. Scully M, Dixon H, Wakefield M. Association between commercial television exposure and fast-food consumption among adults. Public health nutrition. 2009;12(1):105-10.

17. Muscogiuri G, Barrea L, Savastano S, Colao A. Nutritional recommendations for CoVID-19 quarantine. European Journal of Clinical Nutrition. 2020:1-2.

18. Mattioli AV, Sciomer S, Cocchi C, Maffei S, Gallina S. Quarantine during COVID-19 outbreak: changes in Diet and physical activity increase the risk of cardiovascular disease. Nutrition, Metabolism and 
Cardiovascular Diseases. 2020.

19. Macht M. How emotions affect eating: a five-way model. Appetite. 2008;50(1):1-11.

20. Frazão E, Stewart H, Hyman J, Carlson A. Gobbling up snacks: cause or potential cure for childhood obesity? ; 2012.

21. Johnson BJ, Bell LK, Zarnowiecki D, Rangan AM, Golley RK. Contribution of discretionary foods and drinks to Australian children's intake of energy, saturated fat, added sugars and salt. Children. 2017;4(12):104.

22. Aslam MF, Majeed S, Aslam S, Irfan J. Vitamins: Key role players in boosting up immune response-A mini review. Vitam Miner. 2017;6:153.

23. Haddad C, Kheir MB, Zakhour M, Haddad R, Al Hachach M, Sacre H, et al. Association between eating behavior and quarantine/confinement stressors during the Coronavirus disease 2019 outbreak. 2020.

24. Chen P, Mao L, Nassis G, Harmer P, Ainsworth B, Li F. Coronavirus disease (COVID-19): The need to maintain regular physical activity while taking precautions. J Sport Health Sci 2020; 9 (2): 103-4.

25. Owen N, Sparling PB, Healy GN, Dunstan DW, Matthews CE, editors. Sedentary behavior: emerging evidence for a new health risk. Mayo Clinic Proceedings; 2010: Elsevier.

26. Campbell JP, Turner JE. Debunking the myth of exercise-induced immune suppression: redefining the impact of exercise on immunological health across the lifespan. Frontiers in immunology. 2018;9:648.

27. Callaghan P. Exercise: a neglected intervention in mental health care? Journal of psychiatric and mental health nursing. 2004;11(4):476-83.

28. Lippi G, Henry BM, Sanchis-Gomar F. Physical inactivity and cardiovascular disease at the time of coronavirus disease 2019 (COVID-19). European Journal of Preventive Cardiology. 2020:2047487320916823.

29. Hammami A, Harrabi B, Mohr M, Krustrup P. Physical activity and coronavirus disease 2019 (COVID19): specific recommendations for home-based physical training. Managing Sport and Leisure. 2020:1-6.

30. Tate DF, Lyons EJ, Valle CG. High-tech tools for exercise motivation: use and role of technologies such as the internet, mobile applications, social media, and video games. Diabetes Spectrum. 2015;28(1):45-54.

31. Simonnet A, Chetboun M, Poissy J, Raverdy V, Noulette J, Duhamel A, et al. High prevalence of obesity in severe acute respiratory syndrome coronavirus-2 (SARS-CoV-2) requiring invasive mechanical ventilation. Obesity. 2020.

32. Peng Y, Meng K, Guan H, Leng L, Zhu R, Wang B, et al. Clinical characteristics and outcomes of 112 cardiovascular disease patients infected by 2019-nCoV. Zhonghua xin xue guan bing za zhi. 2020;48:E004-E.

33. Lighter J, Phillips M, Hochman S, Sterling S, Johnson D, Francois F, et al. Obesity in patients younger than 60 years is a risk factor for Covid-19 hospital admission. Clinical Infectious Diseases. 2020. 
34. Sattar N, Mclnnes IB, McMurray JJ. Obesity a risk factor for severe COVID-19 infection: multiple potential mechanisms. Circulation. 2020.

35. Radwan H, Ballout RA, Hasan H, Lessan N, Karavetian M, Rizk R. The epidemiology and economic burden of obesity and related Cardiometabolic disorders in the United Arab Emirates: a systematic review and qualitative synthesis. Journal of obesity. 2018;2018.

36. Fadhil I, Belaila BB, Razzak HA. National accountability and response for noncommunicable diseases in the united arab emirates. International Journal of Noncommunicable Diseases. 2019;4(1):4.

37. Xiao H, Zhang Y, Kong D, Li S, Yang N. Social capital and sleep quality in individuals who selfisolated for 14 days during the coronavirus disease 2019 (COVID-19) outbreak in January 2020 in China. Medical science monitor: international medical journal of experimental and clinical research. 2020;26:e923921-1.

38. Sidor A, Rzymski P. Dietary Choices and Habits during COVID-19 Lockdown: Experience from Poland. Nutrients. 2020;12(6):1657.

39. Ibarra-Coronado EG, Pantaleón-Martínez AM, Velazquéz-Moctezuma J, Prospéro-García O, MéndezDíaz M, Pérez-Tapia $M$, et al. The bidirectional relationship between sleep and immunity against infections. Journal of immunology research. 2015;2015.

40. Qiu F, Liang C-L, Liu H, Zeng Y-Q, Hou S, Huang S, et al. Impacts of cigarette smoking on immune responsiveness: up and down or upside down? Oncotarget. 2017;8(1):268.

41. Salk RH, Hyde JS, Abramson LY. Gender differences in depression in representative national samples: meta-analyses of diagnoses and symptoms. Psychological bulletin. 2017;143(8):783.

42. Tannis C, Senerat A, Garg M, Peters D, Rajupet S, Garland E. Improving physical activity among residents of affordable housing: is active design enough? International journal of environmental research and public health. 2019;16(1):151.

43. Zumla A, Hui DS, Perlman S. Middle East respiratory syndrome. The Lancet. 2015;386(9997):9951007.

44. Chan-Yeung M, Xu R. SARS: epidemiology. Respirology 8 Suppl S9-14. 2003.

45. Garnier-Crussard A, Forestier E, Gilbert T, Krolak-Salmon P. Novel Coronavirus (COVID-19) Epidemic: What Are the Risks for Older Patients? Journal of the American Geriatrics Society. 2020.

\section{Figures}




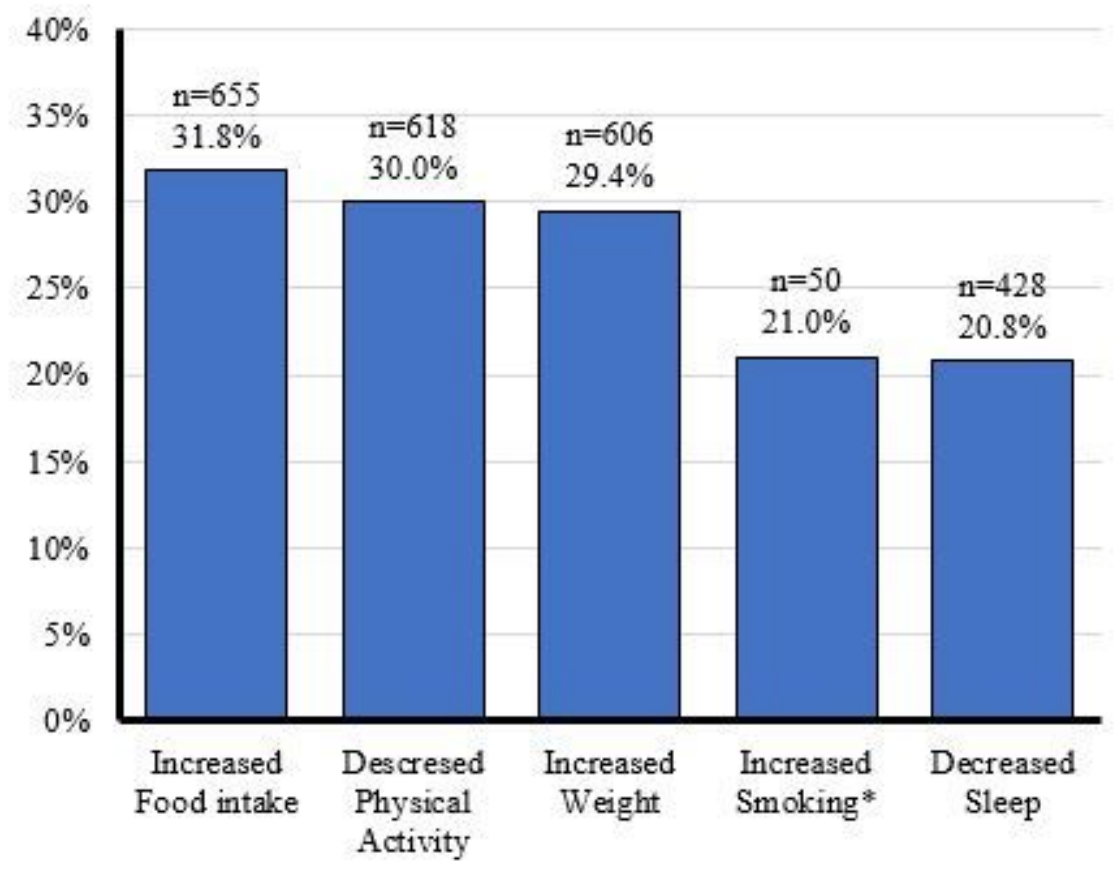

\section{Figure 1}

Prevalence of unhealthy lifestyle behaviors among study participants $(n=2060)$ * Percentage among smokers $(\mathrm{N}=238)$

\section{Supplementary Files}

This is a list of supplementary files associated with this preprint. Click to download.

- AppendixA.CovidLifestyleEngQuestionnaire.doc

- AppendixB.docx 